\title{
Estimating the Cost of Improving Quality in Production Dry Building Mixtures
}

\author{
Valentina Loganina ${ }^{1, a^{*}}$, Tatiana Uchaeva ${ }^{1, b}$ and Maria Zaytseva ${ }^{1, c}$ \\ ${ }^{1}$ Penza State University of Architecture and Construction, Penza, st. Titova,28, Russia \\ aloganin@mail.ru, buchaevatv@mail.ru, czajc@yandex.ru
}

Keywords: Dry Building Mixtures, Quality Costs, Dispersion of Quality Indicators of Products and Raw Materials

\begin{abstract}
Provides information about the cost model associated with improving product quality. On the example of dry building mixtures, the issues of statistical quality management are considered. The cost model takes into account the cost of reducing the bias and variance of raw materials.
\end{abstract}

\section{Introduction}

Analysis of the building materials market shows an increase in the share of dry building mixtures (DBM) for various functional purposes [1,2]. In connection with the increased competition of dry mortar producers, the issues of their quality are of particular relevance.

Measuring control is an important element of product quality management. In the process of control, a comparison of the actually achieved results of quality indicators with the data of regulatory documents is carried out. Any measurement process is associated with variations in its parameters caused by a large number of factors affecting it. This undoubtedly affects the quality indicators of the final product [3-5].

It is known that the variability of the properties of building materials obeys the normal distribution law. With a normal distribution law, the probability that the deviation in absolute value will be less than three times the standard deviation is 0.9973 , i.e. inconsistencies are possible only in $0.27 \%$ of cases.

Let's say the quality of a product is characterized by $m$ properties. With the number of indicators $\mathrm{m}=3$, the probability of obtaining quality products is 0.9919 . However, given that over time, even a well-regulated process can give shifts on average up to 1.5 sigma, it is relevant to take into account the variations in the components of the DBM formulation [6,7].

\section{Materials and research methods}

We analyzed dry construction mixes of the New MIX company (Penza region) (CemPlast, Bundes Koroed B2, Bundes Koroed C3). Cements Sengileevsky CEM I 42.5B (Eurocementgroup), Haldenberg CEM I 42.5N from HeidelbergCement Volga were used for the production of dry mixes. Quartz sand of the Makhalinsky deposit was used as a filler. The values of the standard deviation were calculated for the indicators of compressive strength, moisture content of the dry mixture and water retention capacity, as well as for indicators of cement activity, sand size modulus. The average value of the quality indicator and standard deviation were calculated based on the results of 50 tests.

The probability of compliance with regulatory requirements was calculated using the Laplace function $[8,9]$ 


$$
P\left(\frac{U T-\bar{x}}{\sigma}\right)=2 \Phi(t)=\gamma
$$

or

$$
P\left(\frac{\bar{x}-L T}{\sigma}\right)=2 \Phi(t)=\gamma
$$

where $\sigma$ is the standard deviation;

$U T, L T$ - upper and lower tolerances.

\section{Research results}

The results are shown in Table 1.

Table 1. The probability of defective products

\begin{tabular}{|l|l|}
\hline DBM type & The probability of defective products \\
\hline Cem Plast & $0.00007 / 0.00069$ \\
\hline Bundes Koroed B2 & $0.09011 / 0.13351$ \\
\hline Bundes Koroed C3 & $0.1615 / 0.17881$ \\
\hline
\end{tabular}

Note. Above the line are the values of the probability of the appearance of defective DBM production when using Sengileevsky cement, below the line - Haldenberg cement.

The research results (Table 1) show that the values of the probability of obtaining high-quality dry mixes depend on the type of cement. So, when using Sengileevsky cement, the value of the standard deviation (RMS) of the compressive strength of the DBM CemPlast samples was 1.8 $\mathrm{MPa}$, and when using Haldenberg cement - 2.1 MPa. This difference, in our opinion, is due to the different variability of the cement. So, the values of the standard deviation of the activity of Sengileevsky cement are $\sigma=4.1-5.2 \mathrm{MPa}$, and Haldenberg cement - 4.5-5.7 MPa. Analysis of the data (Table 1) shows that when using Haldenberg CEM I 42.5N cement from HeidelbergCement Volga, the likelihood of defective products increases. So, the probability of the appearance of defective DBM Bundes Koroed B2 is 0.09011 and 0.13351 when using Sengileevsky cement and Haldenberg cement, respectively. Similar patterns are typical for DBM Bundes Koroed C3 and CemPlast

Thus, the choice of the type of cement, as well as other components of the DBM formulation should be carried out taking into account the variability of indicators characterizing their quality. Considering the above, it becomes necessary to analyze the functional relationship between the variability of the quality indicators of the DBM and the variability of the quality indicators of the input variables (raw materials). This will allow, knowing the required variance values of the product quality indicator, to determine the optimal variances of the input variables.

Dry mortar was considered as a system consisting of multiple input variables and one or more output variables. Let $\sigma \mathrm{Y}$ denote the variance of the output variable $\mathrm{Y}$, and $\sigma_{1}, \sigma_{2} \ldots \sigma_{\mathrm{n}}$ denote the variance of the input variables $\mathrm{X}_{1}, \mathrm{X}_{2}, \ldots, \mathrm{X}_{\mathrm{n}}$. We will assume that the controlled parameters are normally distributed random variables. The results of statistical data processing are shown in Table 2. 
For DBM CemPlast, the dependence of the standard deviation of the indicator (RMS) of the compressive strength on the RMS of the indicator of cement activity, the modulus of the size of the sand has the form

$$
Y=a+b x+c x^{2}
$$

Fig. 1 shows a graphical model of the dependence of the standard deviation of the indicator (RMS) of the compressive strength on the RMS of the indicator of cement activity. The values of the coefficients in the model (2) for the RMSD of the cement activity are equal to $\mathrm{a}=5.031 ; \mathrm{b}=\mathrm{-}$ $2.3 ; \mathrm{c}=0.32$. The correlation coefficient is $\mathrm{r}=0.996$

Table 2. Variability of quality indicators for dry mixes and raw materials

\begin{tabular}{|l|l|l|}
\hline \multicolumn{2}{|c|}{ Standard deviation } \\
\hline Haldenberg (activity) & Sengeleevsky (activity) & Sand (fineness module) \\
\hline $4.5 / 1.18$ & $4.1 / 1.05$ & $0.16 / 1.1$ \\
\hline $4.7 / 1.24$ & $4.2 / 1.1$ & $0.18 / 1.3$ \\
\hline $4.9 / 1.4$ & $4.6 / 1.3$ & $0.23 / 1.5$ \\
\hline $5.23 / 1.8$ & $4.9 / 1.6$ & $0.267 / 1.92$ \\
\hline $5.7 / 2.3$ & $5.2 / 1.8$ & $0.8 / 2.3$ \\
\hline
\end{tabular}

Note. Above the line are the values of the root-mean-square deviation of the activity of cement and the modulus of sand size, below the line - the compressive strength of DBM-CemPlast.

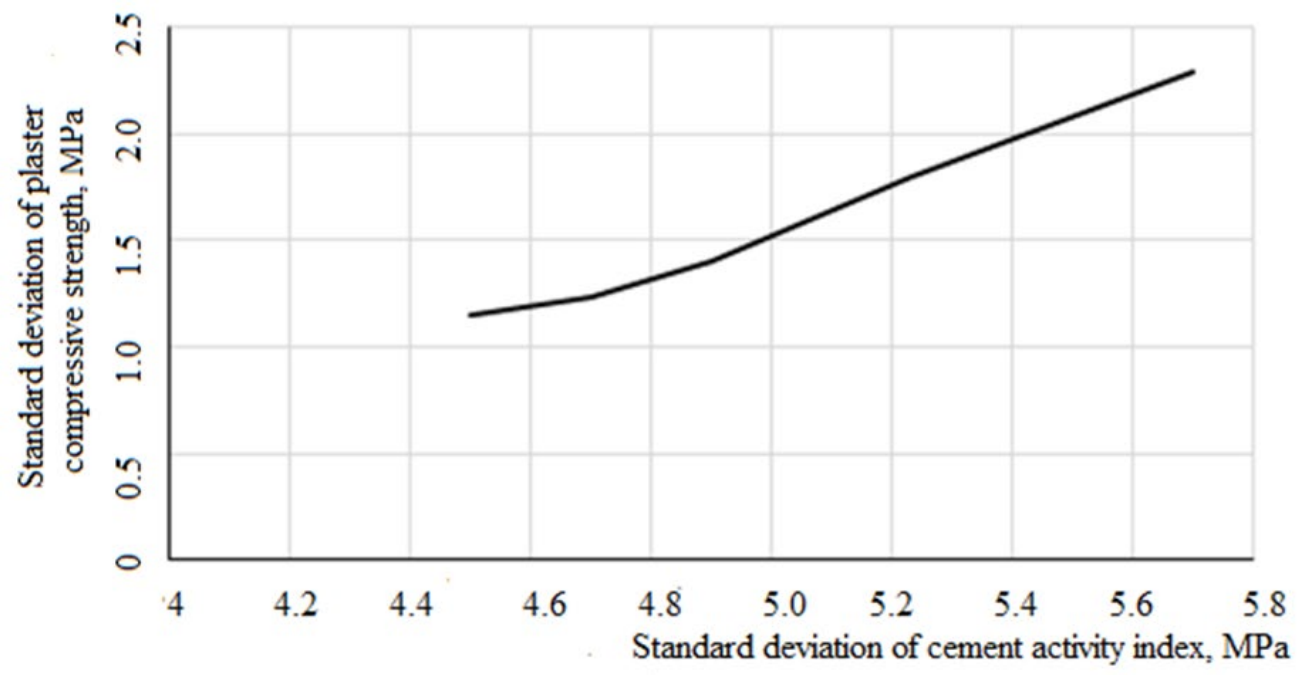

Fig. 1. Dependence of the standard deviation of the compressive strength of CemPlast plaster on the value of the standard deviation of the cement activity indicator

Using the proposed models, it is possible to clarify the requirements for the RMS of raw materials quality indicators. So, for example, with a compressive strength equal to $12.43 \mathrm{MPa}$, the standard deviation is $\sigma=1.91 \mathrm{MPa}$, and the value of the coefficient of variation is $v=15.36 \%$. With the tightening of the requirements for the scatter of data on the strength index of DBM to $v$ 
$=10.0 \%(\sigma=1.243 \mathrm{MPa})$, the value of the RMSD of the cement activity should be in accordance with formula (2) $\sigma=4.7 \mathrm{MPa}$.

The ultimate goal of a statistical management strategy is to minimize the overall cost to both producer and consumer, or the cost of the entire system. The cost to the consumer is related to the expected loss of quality of the output variable and is caused by the deviation from the target value. The costs to the producer are associated with the changing probability distribution of the input variables.

Let us consider a model of costs for improving product quality, which consists in taking into account the average values and variance values of quality indicators. The expected loss of quality for the customer consists of two parts: process bias and process deviation. The bias reduction strategy is to tune the workflow until the expected quality metric matches the target value. To reduce the variance of the $\mathrm{Y}$ exponent, the designer must reduce the variance of the input variables, which will also increase the cost. The challenge is to balance the reduced expected loss of quality with the increased cost of reducing the bias and variance of the input variables [10-12]. We denote the cost of variance control for the $\mathrm{i}$-th input variable $\mathrm{Xi}$ as $\sum_{i=1}^{n} C_{i}\left(\sigma_{i}^{2}\right)$ and the control cost for the $\mathrm{i}$-th input variable $\mathrm{Xi}$ as $D_{i}\left(\mu_{i}\right)$. The general model is:

$$
T C=\sum_{i=1}^{n} C_{i}\left(\sigma_{i}\right)^{2}+\sum_{i=1}^{n} D_{i}\left(\mu_{i}\right)+k\left[\sigma_{y}^{2}+\left(\mu_{i}-y_{o}\right)^{2}\right]
$$

where $k\left[\sigma_{y}^{2}+\left(\mu_{i}-y_{o}\right)^{2}\right]$ is the expected loss of quality for the consumer; $\mathrm{k}$ is a constant in the quality loss function; $\mathrm{Y}_{0}$ is the target $\mathrm{Y}$ value.

In equation (3), the first two terms $\sum_{i=1}^{n} C_{i}\left(\sigma_{i}^{2}\right)$ and $\sum_{i=1}^{n} D_{i}\left(\mu_{i}\right)$ are the costs of variances and the mean values of the input variables or cost to the manufacturer.

Consider the costs of the manufacturer of the DBM. If the average value of cement activity does not correspond to the target value $\mathrm{Y}_{0}$ and the standard deviation $\sigma$ does not provide a low variability of the quality indicator of the DBM, then the DBM manufacturer is not able to change anything in regulating the quality of cement, therefore, the cement supplier should be changed to another, supplied cement with a lower variability. In this case, the manufacturer of the DBM does not incur additional costs. Sand for dry mixes must comply with GOST 8736-93 "Sand for construction work. Technical conditions". As a rule, graded sand is used for DBM. If the variability of the sand does not suit the manufacturer of dry mixes from the point of view of the variability of the quality of dry mixes, then the costs of the manufacturer will be determined either by the purchase of a classifier that allows obtaining two or three fractions of sand, or by the purchase of fractionated sand.

\section{Conclusion}

A correlation has been established between the variability of the quality indicators of dry building mixtures and the variability of the quality of the components of the DBM formulation.

A cost model is proposed that takes into account the costs of reducing the bias and variance of raw materials. The proposed approach will allow regulating the quality of products already at the design stage and will minimize costs for both the manufacturer and the consumer.

\section{References}

[1] Market of building (concrete) mixtures in Russia: research and forecast until 2025 Release: October, 2021 https://roif-expert.ru/stroitelstvo/stroitel-nye-smesi/rynok-stroitel-nyh-betonnyhsmesej/rynok-stroitel-nyh-betonnyh-smesej-v-rossii-obzor-i-prognoz.html 
[2] Analysis of dry mortar in Russia in 2015-2019, assessment of the impact of coronavirus and forecast for $2020-2024$

https://businesstat.ru/images/demo/dry_building_mix_russia_demo_businesstat.pdf

[3] V.I. Loganina, Evaluation reliability of the control building materials and products for stability technological processes of production, Contemporary Engineering Sciences.7(33-36) (2014) 1927-1933. https://doi.org/10.12988/ces.2014.411207

[4] V.I. Loganina, J.P. Skachkov, T.V. Uchaeva, Assessment of the stability of the staining process of building products and constructions, International Journal Of Applied Engineering Research. 11(19) (2016) 9727-9729

[5] V.I. Loganina, Y.P.Skachkov., V.S. Lesovik, Quality control of building materials according to uncertainty of measurement and stability of the technological process of production.Solid State Phenomena. 299 (2020) 1161-1165. https://doi.org/10.4028/www.scientific.net/SSP.299.1161

[6] N.A. Rubichev, V.D. Frumkin, Reliability of tolerance quality control, Moscow, Publishing house of standards, 1990 .

[7] V.E. Gmurman, Probability theory and mathematical statistics: textbook for universities, Moscow, Yurayt Publishing House. 2020

[8] Yu.P Adler, B.L. Rozovsky, Operational statistical quality management. Moscow: Knowledge. 1984; 102

[9] E. Shindlovsky, O. Shchurts, Statistical methods of quality management, Moscow, Mir. 1976.

[10] L.V. Condra, Reliability Improvements with Design of Experiments, Marcel Dekker, Inc., New York, 2001

[11] M.Rausand, and A. Hoyland, System Reliability Theory: Models, Statistical Methods and Applications, 2nd ed., Wiley-Interscience, Hoboken, NJ, 2003

[12] Z.G. Stoumbos, M.R., Reynolds, T.P. Ryan and W.H Woodall, The State of Statistical Process Control as We Proceed into the 21st Century, Journal of the American Statistical Association. 95 (2000) 992-998. https://doi.org/10.1080/01621459.2000.10474292 